\title{
Effects of Burial by the Disposal of Dredged Materials from the Columbia River on Pacific Razor Clams (Siliqua patula)
}

J. Vavrinec

N. P. Kohn

K. D. Hall

B. A. Romano

January 2007

Final Report

Prepared for

the U.S. Army Corps of Engineers, Portland District

Portland, Oregon

under a Related Services Agreement

with the U.S. Department of Energy

Contract DE-AC05-76RL01830 


\title{
DISCLAIMER
}

This report was prepared as an account of work sponsored by an agency of the United States Government. Neither the United States Government nor any agency thereof, nor Battelle Memorial Institute, nor any of their employees, makes any warranty, express or implied, or assumes any legal liability or responsibility for the accuracy, completeness, or usefulness of any information, apparatus, product, or process disclosed, or represents that its use would not infringe privately owned rights. Reference herein to any specific commercial product, process, or service by trade name, trademark, manufacturer, or otherwise does not necessarily constitute or imply its endorsement, recommendation, or favoring by the United States Government or any agency thereof, or Battelle Memorial Institute. The views and opinions of authors expressed herein do not necessarily state or reflect those of the United States Government or any agency thereof.

\author{
PACIFIC NORTHWEST NATIONAL LABORATORY \\ operated by \\ BATTELLE \\ for the \\ UNITED STATES DEPARTMENT OF ENERGY \\ under Contract DE-AC05-76RL01830
}

Printed in the United States of America
Available to DOE and DOE contractors from the
Office of Scientific and Technical Information,
P.O. Box 62, Oak Ridge, TN 37831-0062;
ph: (865) 576-8401
fax: (865) 576-5728
email: reports@adonis.osti.gov

\author{
Available to the public from the National Technical Information Service, \\ U.S. Department of Commerce, 5285 Port Royal Rd., Springfield, VA 22161 \\ ph: (800) 553-6847 \\ fax: (703) 605-6900 \\ email: orders@ntis.fedworld.gov \\ online ordering: http://www.ntis.gov/ordering.htm
}

Ty 
PNNL-16350

\title{
Effects of Burial by the Disposal of Dredged Materials from the Columbia River on Pacific Razor Clams (Siliqua patula)
}

\author{
J. Vavrinec \\ N. P. Kohn \\ K. D. Hall \\ B. A. Romano
}

Marine Sciences Laboratory

Sequim, Washington

January 2007

Final Report

Prepared for

the U.S. Army Corps of Engineers, Portland District

Portland, Oregon

under a Related Services Agreement

with the U.S. Department of Energy

Contract DE-AC05-76RL01830

Pacific Northwest National Laboratory

Richland, Washington 99352 



\section{Executive Summary}

Annual maintenance of the Columbia River navigation channel requires the U.S. Army Corps of Engineers (Corps) to dredge sediment from the river and dispose of the sediment in coastal areas at the mouth of the Columbia River. Some of these disposal areas can be as shallow as $12 \mathrm{~m}$ deep in waters off the coastal beaches, and dredged material disposal activities have therefore raised concerns of impacts to local razor clam (Siliqua patula) populations that are prevalent in the area. The Corps' Portland District requested that the Marine Sciences Laboratory of the U.S. Department of Energy's Pacific Northwest National Laboratory conduct laboratory experiments to evaluate the potential impacts of burial by dredged material to razor clams during disposal.

Prior modeling of disposal events indicates three stresses that could have an impact on benthic invertebrates: convective descent and bottom encounter (compression forces due to bottom impact), dynamic collapse and spreading (surge as material washes over the bottom), and mounding (burial by material). Because the razor clam is infaunal, the effects of the first two components should be minimal, because the clams should be protected by substrate that is not eroded in the event and by the clams' rapid digging capabilities. The mound resulting from the disposal, however, would bury any clams remaining in the footprint under as much as $12 \mathrm{~cm}$ of new sediment according to modeling, and the clams' reaction to such an event and to burial is not known. Although the literature suggests that razor clams may be negatively affected by siltation and therefore perhaps by dredging and disposal activity, as well, impacts of this type have not been demonstrated.

The primary purpose of this study was to evaluate the potential impacts of dredge material disposal on adult subtidal razor clam populations at the mouth of the Columbia River. Using the parameters defined in a previous model, a laboratory study was created in which a slurry was added to experimental chambers seeded with adult razor clams to produce burial mounds of various thicknesses. The laboratory results presented here have two implications for disposal operations.

First, the laboratory results from this study indicate that the razor clam populations can survive the range of burial depths predicted from the type of disposal operations that the Corps currently conducts (i.e., single disposal in any location). According to the model outcomes, a disposal event during typical operations would produce a maximum potential burial mound about $12 \mathrm{~cm}$ in thickness, and a mound of $12 \mathrm{~cm}$ height would cover an area of the sea bottom estimated at $9000 \mathrm{~m}^{2}$. The present results suggest that razor clams can tolerate burial, and then successfully regain access to the water column. After a single disposal event, clam survival was $100 \%$ for burial up to $12 \mathrm{~cm}$, and survival was still high (70\%) when the $12 \mathrm{~cm}$ depth was doubled to $24 \mathrm{~cm}$.

Second, the laboratory results suggest that mortality is increased as the time intervals between burial events decrease. When the frequency of the disturbance was increased, clam survival decreased but was still relatively high. This was particularly apparent when comparing the survival after two $12 \mathrm{~cm}$ burial events 4 hours apart (50\%) with that in a single $24 \mathrm{~cm}$ burial event (nearly $70 \%$ ). Both events resulted in the same overall burial depth. The mechanism that leads to the higher mortality with multiple burial 
events is unknown. The present data suggest that it could possibly minimize loss to the broodstock population if at least 24 hours were allowed between disposal events. Most of the clams buried in one disposal event would regain access to the surface after this time interval, and direct survival estimates are high. Trials that included a third burial event at a 24-hour interval resulted in the same survival rate as did those with two burials (87\%), suggesting that clams that are able to survive two sequential disposal events can survive another at a similar 1-day time interval. This was not the case when time interval between burial events was shorter (4 hours); in these trials, all clams died after a third event. 


\section{Contents}

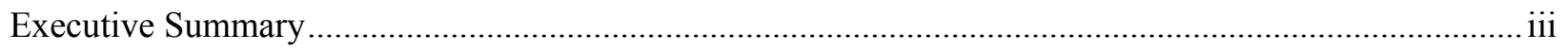

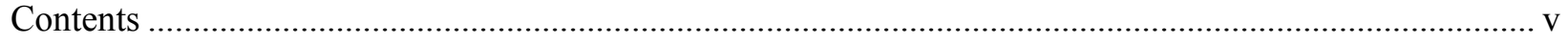

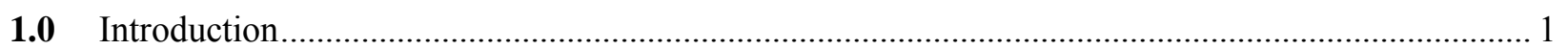

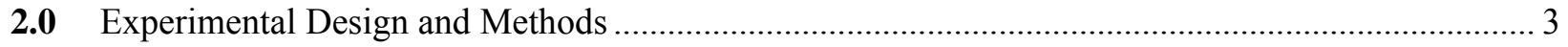

2.1 Environmental Parameters Based on Previous Modeling of Disposal Events......................... 3

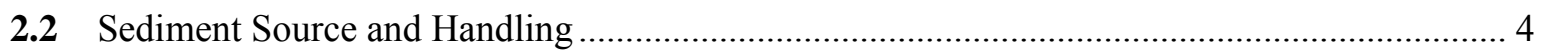

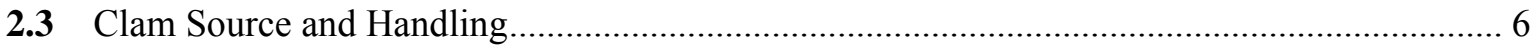

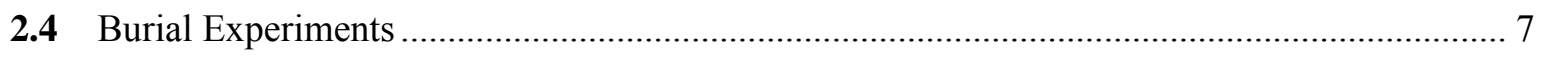

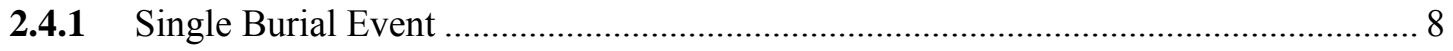

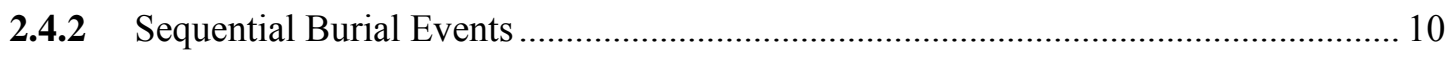

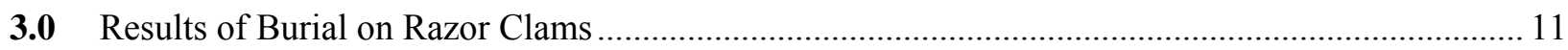

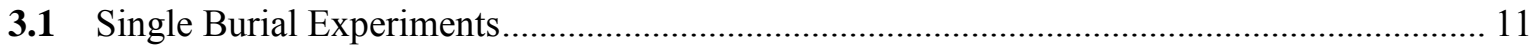

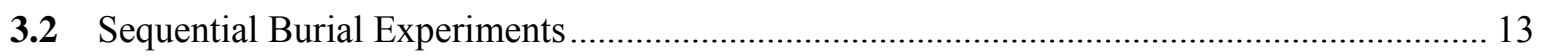

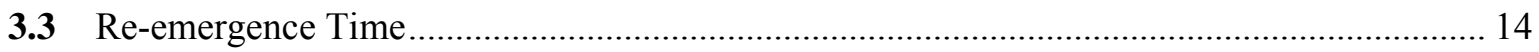

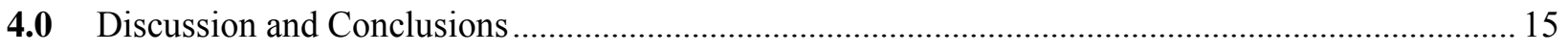

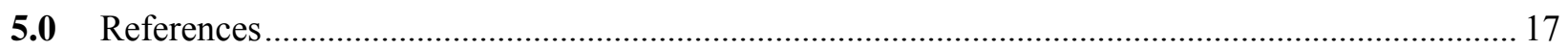




\section{Figures}

Figure 1. Grain size distribution of MCR sand and experimental Arness sand........................................ 4

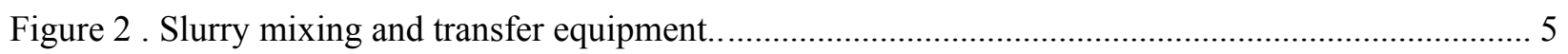

Figure 3. Experimental chambers in various stages of the experiment..................................................... 7

Figure 4. Photographs of some components of the burial sequence ......................................................... 9

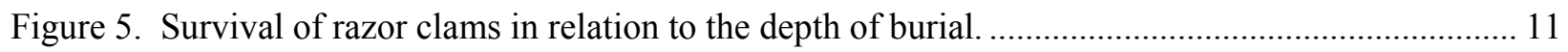

Figure 6. Survival of razor clams exposed to multiple burials............................................................... 13

Figure 7. Reemergence times after burial for clams in three disposal scenarios .................................... 14

\section{Tables}

Table 1. Maximum predicted mound thickness from STFATE Model with Columbia River vessels (modified from Pearson et al. 2006). 3

Table 2. Results of single and sequential razor clam burial trials. 12 


\subsection{Introduction}

Annual maintenance of the Columbia River navigation channel requires the U.S. Army Corps of Engineers (Corps) to dredge sediment from the river and dispose of the sediment in coastal areas at the mouth of the Columbia River (MCR). Some of these disposal areas can be as shallow as $12 \mathrm{~m}$ deep in waters off the coastal beaches, and dredged material disposal activities have therefore raised concerns of impacts to local razor clam (Siliqua patula) populations that are prevalent in the area. The Corps' Portland District requested that the Marine Sciences Laboratory (MSL) of the U.S. Department of Energy's Pacific Northwest National Laboratory (PNNL) conduct laboratory experiments to evaluate the potential impacts of burial by dredged material to razor clams during disposal.

Razor clams are an important resource in the Pacific Northwest (PNW), and a large proportion of the total harvest occurs at the MCR along Clatsop Beach in northwest Oregon (Braun 2005). The majority of the razor clams appear to be intertidal and most of the commercial harvest is focused there (Lassuy and Simons 1989). These productive intertidal beds should be safe from the dredge disposal because there will be considerable distance between the beds and the dumping sites (pers. comm. K. Larson, Corps.). However, there are subtidal populations of razor clams found off these beaches (along with a congener, $S$. sloati) and some speculate that these subtidal populations of $S$. patula may be the broodstock for the commercially important intertidal beds (Schink et al. 1983). While the exact subtidal distribution of $S$. patula is not quantified (see Lassuy and Simons 1989 for review), they have been found in waters at least $6 \mathrm{~m}$ deep in the PNW and commercially harvested in Alaska down to $12 \mathrm{~m}$. Given the limited lateral movement in razor clams (Lassuy and Simons 1989), these subtidal clams could be exposed to a disposal event.

Modeling done on disposal events indicate three stresses that could impact benthic invertebrates (Pearson et al. 2006): Convective Decent and Bottom Encounter (compression forces due to bottom impact), Dynamic Collapse and Spreading (surge as material washes over the bottom), and Mounding (burial by material). Since the razor clam is infaunal, the effects of the first two components should be minimal as the clams should be protected by any substrate not eroded in the event and their rapid digging capabilities. The mound resulting from the disposal, however, would bury any clams in the footprint under as much as $12 \mathrm{~cm}$ of new sediment. Although razor clams are known to be fast diggers into the sediment (e.g. McLachlan et al. 1995), how they react to a disposal event and burial is not known. Although the literature suggest that razor clams may be negatively impacted by siltation (Lassuy and Simons 1989) and therefore perhaps by dredging and disposal activity, such potential impacts have not been demonstrated.

Razor clam survival of burial events is most likely related to the frequency and intensity of the disturbances. Normal operations during dredge disposal at the MCR intentionally spread the material over space and time (pers. comm. D. McKillip, Corps.) and would, consequently, limit the number of burials to which a particular clam might be exposed. There are some scenarios, however, that would require multiple disposal events in a short period of time to build up material on the bottom. It is therefore important to determine the impacts of single and multiple disposal scenarios with a variety of overburden depths to accurately predict impacts to populations of razor clams in areas where dredge disposal is occurring. 
Specifically, the objectives of this laboratory study were to:

- Determine the survival of razor clams when buried under sediment of various thicknesses up to $20 \mathrm{~cm}$.

- Determine the immediate and delayed survival of clams exposed to a series of burial events as might be experienced with multiple loads deposited from a dredge over the course of a day's sediment placement activities.

- Determine the time required for the razor clams to reestablish siphon contact to the sedimentwater interface after burial. 


\subsection{Experimental Design and Methods}

\subsection{Environmental Parameters Based on Previous Modeling of Disposal Events}

The goal of this research is to realistically mimic the conditions to which the razor clams would be exposed during a disposal event, to the extent as possible in the laboratory. Physics-based numerical models created to predict the dynamics of a disposal event were used as guides in establishing both the parameters of the experimental design and the physical requirements for mound formation.

Pearson et al. (2006) used the Short-term Fate (STFATE) dredged material disposal model developed by the Corps' Engineer Research and Development Center in Vicksburg, Mississippi, to estimate the magnitude of the three parameters thought to affect Dungeness crab (Cancer magister) referenced earlier: 1) pressure developed by the convective descent, 2) horizontal shear stress generated during dynamic collapse, and 3) burial following settling of the dredged materials. A matrix of disposal conditions was developed for the two dredges most likely to be used in the Lower Columbia River dredging operations, the Essayons and the Sugar Island, resulting in 36 test scenarios modeled in STFATE. The simulations indicate that the mound from a single disposal event in $13.7 \mathrm{~m}$ deep water from the dredge Essayons could have a maximum thickness of $12.6 \mathrm{~cm}$ (Table 1). A Columbia River Nearshore Beneficial Use Project presentation (Greenwood 2005) reported similar modeling results for the area and estimated a layer of sediment approximately $9 \mathrm{~cm}$ deep (maximum) from an Essayons dump in slightly deeper (19 m) water. In both studies, this maximum burial depth decreased dramatically with distance from the point of impact. Based on the results of these studies, a burial depth of $12 \mathrm{~cm}$ was chosen as the standard for this study. Mortality is likely to be highest at the maximum predicted depth and the results would be the most conservative for determining risks to the population.

Table 1. Maximum predicted mound thickness from STFATE Model with Columbia River vessels (modified from Pearson et al. 2006).

\begin{tabular}{lccc}
\hline \multicolumn{1}{c}{ Vessel Name } & Water Depth (ft) & Discharge Duration (min) & Mound Thickness $^{\mathbf{a}} \mathbf{( c m )}$ \\
\hline Essayons & 45 & 9 & 12.6 \\
Essayons & 65 & 9 & 9.7 \\
Essayons & 230 & 9 & 6.2 \\
Essayons & 280 & 9 & 5.3 \\
Essayons & 45 & 14 & 9.6 \\
Essayons & 65 & 14 & 7.6 \\
Essayons & 230 & 14 & 4.4 \\
Essayons & 280 & 14 & 3.9 \\
Sugar Island & 45 & 3 & 10.8 \\
Sugar Island & 65 & 3 & 8.2 \\
Sugar Island & 230 & 3 & 2.7 \\
Sugar Island & 280 & 3 & 2.3 \\
\hline
\end{tabular}

a. Maximum vertical impact and shear stresses were predicted when dredge traveled across (perpendicular to) bottom slope. 
Additional information was obtained from the conceptual model used in Pearson et al. (2006) in describing the nature of the burial mechanics. During the disposal event, the dredge material entrains water through turbulent mixing as it falls through the water column. This means that a slurry of water and sediment is actually arriving at the sea floor and any burial mound will form from sand settling out of this slurry. The sediment delivery system described below was constructed to introduce the sediment to the experiment as a slurry to best mimic the natural conditions of a disposal event.

\subsection{Sediment Source and Handling}

Use of the appropriate sediment in the clam studies is important to produce results applicable to dredge material disposal in the MCR and reduce experiment artifacts. Razor clam distributions may be partially limited by the sediment composition in different habitats, especially if there is a significant clay or very fine component in the grain size distribution (reviewed in Lassuy and Simons 1989). Grain size distribution for MCR sediment is available from several previous studies (Gailiani et al. 2003, Hammermeister 2006). Hammermeister (2006) found that the sediment grain composition in the dredge material was similar to the native sediment at the disposal site, so the same sediment characteristics can be used for both substrate and slurry in the laboratory trials. An average of these analyses indicates that MCR sediments are predominantly medium and fine sand. Numerous sources of sand were investigated, attempting to match the MCR sand grain size distribution as closely as possible with sand from one source. Mixing sand from two sources was also considered as an option for obtaining the appropriate grain size distribution. The best available option was "Arness sand" (Blake Sand and Gravel, Sequim, Washington), for which grain size distribution is compared with MCR sediment in Figure 1. This sand

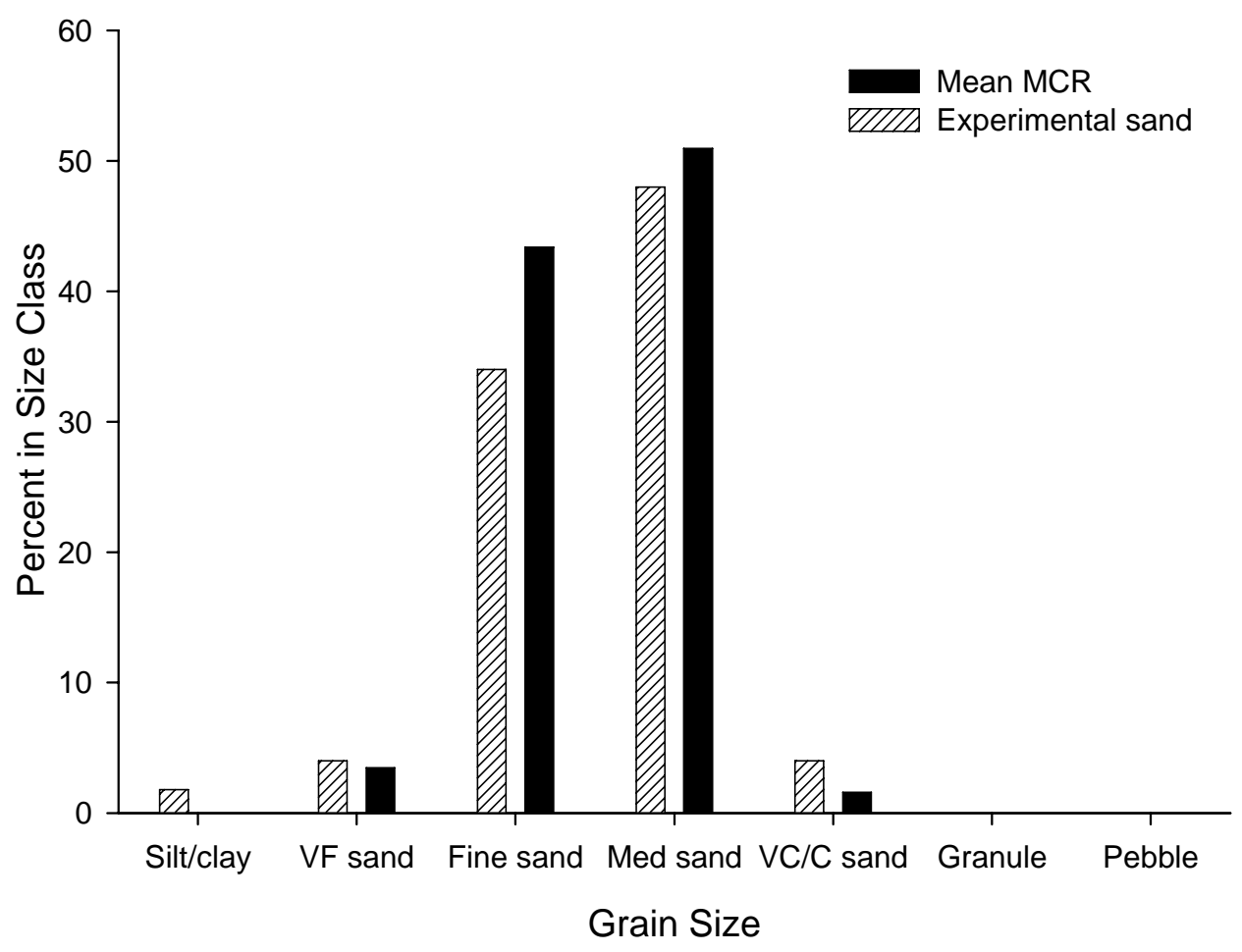

Figure 1. Grain size distribution of MCR sand and experimental Arness sand. 
was considered representative of MCR without mixing with another sand source and approved by the Corps and resource agencies. The sand was coarse sieved through a 2-mm sieve before use to protect the slurry pump from larger stones.

Several methods were employed to mix the sand with water to make slurry and keep it in suspension. Mixing occurred in $378 \mathrm{~L}$ (100 gal) tank (Figure 2), and the slurry needed to be kept in suspension during movement to the experimental tanks. We first used an electric mixing motor (Leeson .25 HP Model C4C17FB21D) with the standard 3-blade mixing prop supplied with it. This configuration succeeded in suspending small amounts of sand, but when we added sand sufficient for deeper burial exposures there was heavy accumulation around the bottom edges of the tank. The small prop was replaced with a new mixing blade used for mixing drywall plaster, but the new blade in the slurry tended to overload the motor. The motor was replaced with an electric direct drive motor (Eberbach Con Torque \#7265). This produced a large vortex in the tank that would spin the sand off to the corners of the mixing tank. A ring to supply pressurized air was fashioned into the bottom edge of the mixing tank to resuspend the material settling there, but this was only partially successful. Finally, we placed an electric trolling motor (Minn Kota Endura 44) into the mixing tank and this succeeded in suspending the mixture with only minor accumulations in eddies that could be resuspended by hand with a mixing pole. We believe that the mixing motors were producing too much centrifugal force and effectively spinning the sand out of solution. The boat motor, with its thrust directed slightly down, appeared to provide more turbulent water movement that could keep the sand in suspension.

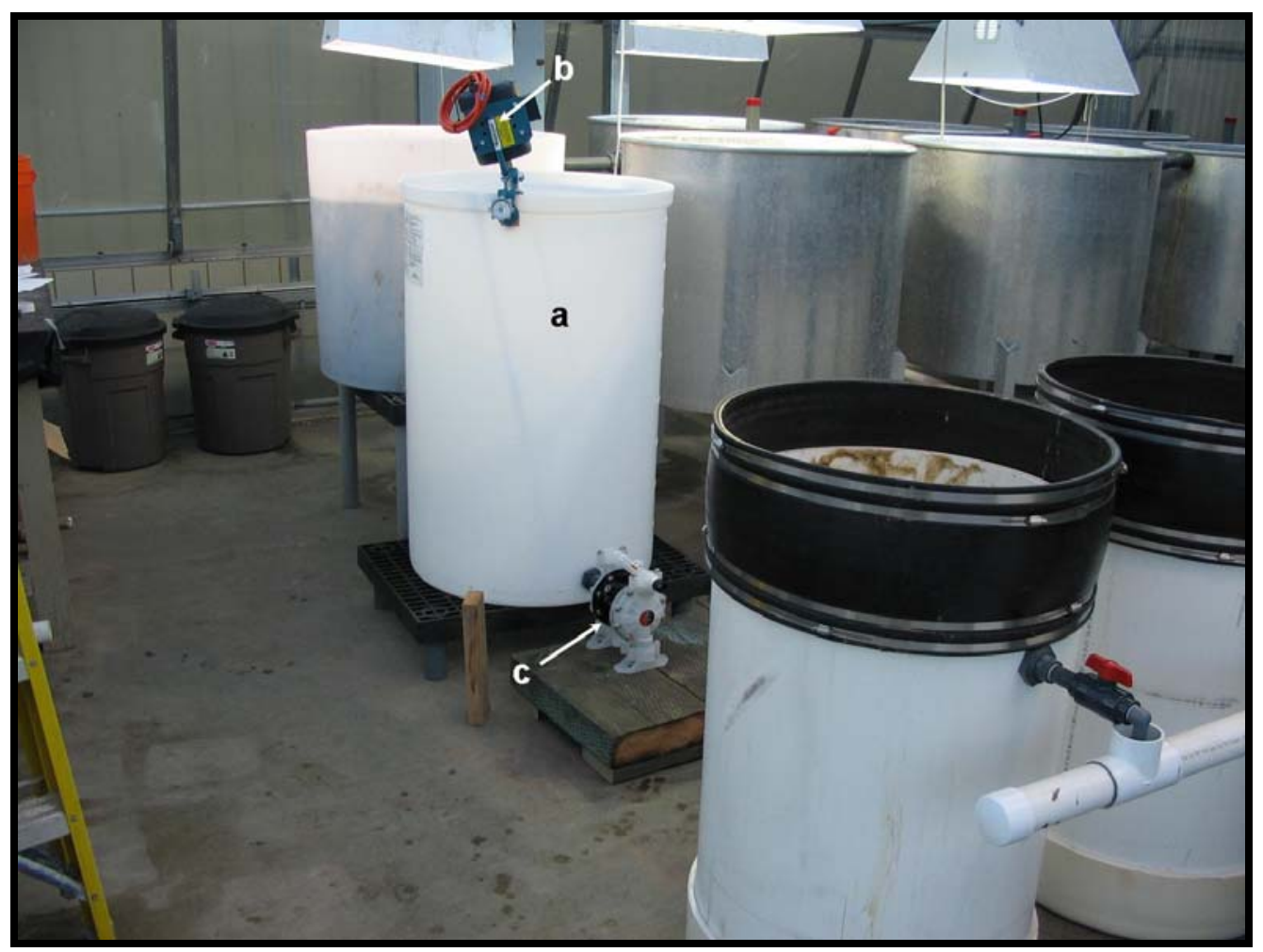

Figure 2 . Slurry mixing and transfer equipment. Components include: a) mixing tank; b) mixer; and c) double diaphragm slurry pump. 
A polypropylene double diaphragm slurry pump (Husky 515) was used to transfer the slurry from the mixing tank to the experimental tanks (Figure 2). This pneumatically driven pump employed pressurized air drawn from the compressed air MSL system at a maximum pressure of $100 \mathrm{psi}$. This pump proved to be quite effective as long as care was taken to ensure the pump did not become impacted with sand.

\subsection{Clam Source and Handling}

Live razor clams were collected by the Oregon and Washington Departments of Fish and Wildlife (ODFW and WDFW) during their annual population surveys. The first clams were taken from beaches close to the MCR. A second batch of clams was collected by the WDFW along Washington's midcoast for use in later experiments. Mature razor clams ( $\geq 10 \mathrm{~cm}$; Lassuy and Simons 1989) were used in the experiments because the primary concern was for subtidal broodstock populations, although four juveniles were tested due to their availability. These clams were transported to the MSL and placed into holding tanks for acclimation to the MSL seawater system. The circular holding tanks were approximately $1 \mathrm{~m}$ in diameter. At least $0.3 \mathrm{~m}$ of sand was placed in the bottom of the tanks to allow the clams to completely bury into the substrate. This appears to be vary important for holding razor clams since the sediment is required to enable the clam to hold the valves shut without fatigue. A continuous flow of unfiltered seawater from Sequim Bay to the tanks provided food for the clams as well as maintenance of ambient water temperatures in the tanks.

The experimental chambers were constructed of 24 inch (approximately $0.6 \mathrm{~m}$ ) diameter Schedule 80 PVC pipe placed on end (Figure 3). The lower end was sealed with a flat pipe cap. The bottom, permanent section of the experimental chamber was approximately $1 \mathrm{~m}$ high and filled with at least $0.3 \mathrm{~m}$ of the Arness sand as substrate for the clams. This section was plumbed to deliver raw, unfiltered seawater and the drain could be stopped for the addition of slurry. A flexible rubber coupling allowed a second $1 \mathrm{~m}$ pipe section to be placed on top of the base section and effectively create a chamber about 2 $\mathrm{m}$ tall. This additional section doubled the volume of the chamber in order to handle the addition of the slurry. The top section could be removed after the slurry had settled to enable observation and access to the clams in the bottom section.

The razor clam holding and experimental chambers were plumbed so effluent went through the MSL wastewater treatment system prior to discharge to Sequim Bay. In this system, potentially contaminated wastewater is treated by a process that consists of settling, particulate filtration, disinfection, and adsorption. This precaution was taken because ODFW and WDFW indicated that the razor clams were collected from populations that may contain some levels of the Nuclear Inclusion X (NIX) pathogen common along the coast.

Clams used in the experiments appeared healthy and had a vigorous siphon withdrawal response. In general, we tried to use each clam only once for experiments, but a few clams were used a second time during the last sequential burial experiments as naïve clams were becoming scarce. Only clams that were healthy and had not been used in an experiment for more than a week were considered eligible for reuse. Clams were destroyed after they were used in the experiments. 


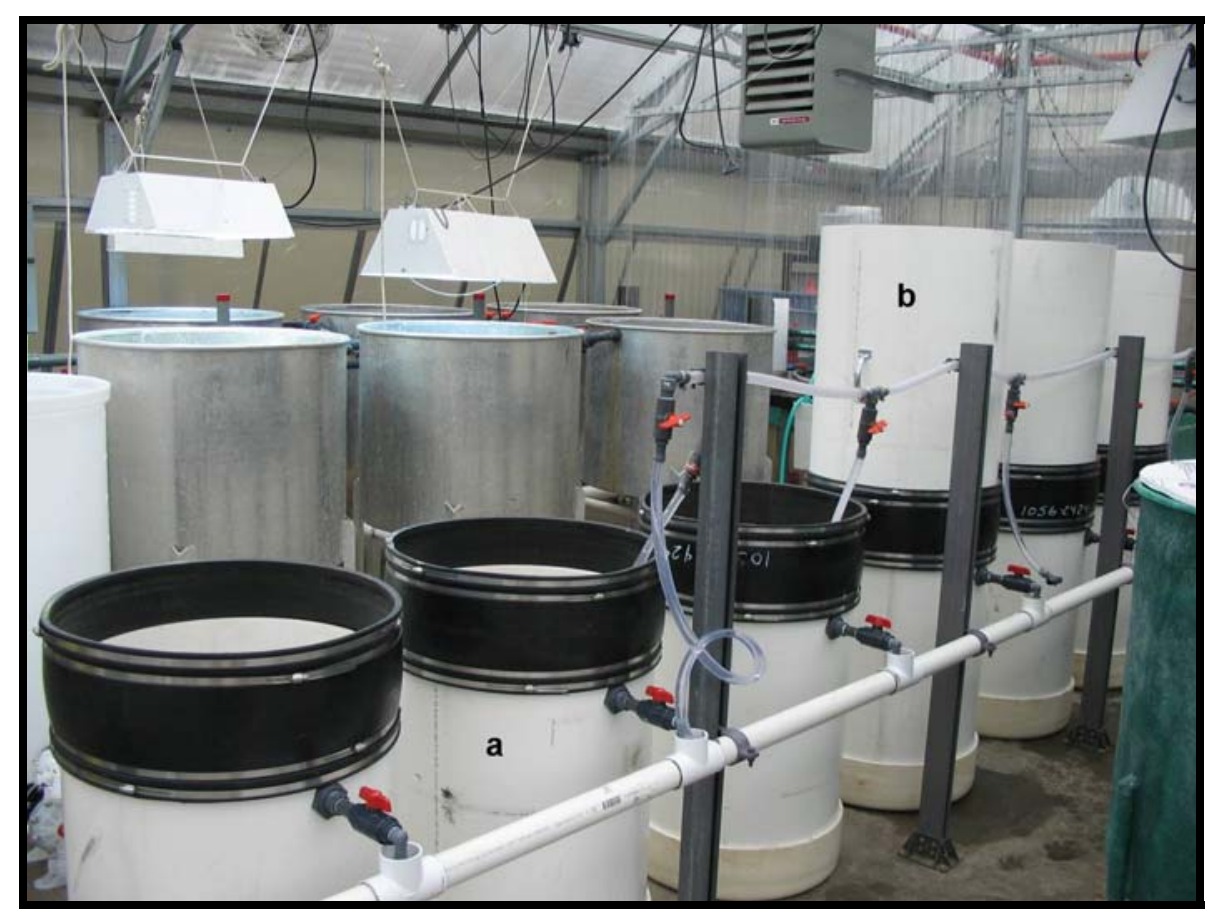

Figure 3. Experimental chambers in various stages of the experiment. Each chamber comprised a lower permanent tank (a) and a removable top section (b).

\subsection{Burial Experiments}

The overall objective of this study is to determine the effects of burial on infaunal razor clams. Although the burial depth or number of burial events changed with the experimental trial, the process of creating and adding slurry to the experimental tanks remained the same.

Experimental chambers were conditioned with raw seawater and then prepared before each experimental burial. Healthy clams were measured for length and placed into the experimental chambers at least 12 hours prior to the first slurry exposures. This allowed time for the clams to burrow and acclimate to the tanks before any experimental treatment. Three clams were placed in each experimental chamber to prevent crowding. The location of each clam was noted after introduction to the chamber. Short pieces of angled aluminum were also placed along the perimeter of the chamber away from the clams, with one side lying on top of the sediment and the other anchoring the metal into the sediment. These aluminum pieces were used as a marker for the original substrate location to later measure actual depth of the burial mound. A control was established for each set of trials where three clams were handled (moved from the holding tank and measured) and placed in one of the experimental chambers,

Once the razor clams had acclimated and were visually checked again for viability, the chambers were prepared for the burial event. First, the water flow to the chamber was shut off and the drain closed. The top section of the experimental chamber was placed into the rubber coupler on the lower section and fastened into place with two large hose clamps. A measured quantity of sand to yield the target burial depth was added to approximately $280 \mathrm{~L}$ of unfiltered seawater in the slurry tank and mixed with the 
electric motor (Figure 4A and B). A pole was used to resuspend any sand that settled out in the few eddies and to keep the drain in the slurry tank clear (Figure 4C). The slurry was then pumped through double diaphragm pump and garden hose to the experimental chamber. At least $30 \mathrm{~cm}$ of water remained above the sediment in the experimental chamber to diffuse any energy from the introduction of the slurry and prevent excavation of the substrate. Additionally, the slurry was initially run along the chamber wall

(Figure 4E) until the water column became deeper. Then the hose was moved around to evenly distribute the sand in the tank (Figure 4D). The control did not have slurry added.

The amount of slurry was calculated so the whole volume fit in the modified experimental tank without overflow and subsequent loss of sand. The slurry transfer generally took between 10 and 20 minutes to complete. The tank was then left to allow the sand to settle out of solution. After four hours, most of the water was decanted out of the experimental tanks, the top section of each tank was removed, and seawater flow was restored. Observations were made as soon as the water was clear enough to see the substrate and determine whether the clams had regained the sediment water-interface. Siphon holes were easily seen as a disturbance in the fine sand on the substrate surface and observations on the time needed for the clams to regain the surface were made. The experiment ended 72 hours after the last burial event or when it was evident that all clams had regained the sediment-water interface. After that time, the depth of the burial layer was determined by pushing a ruler into the sediment until it hit the angled aluminum at the pre-disposal substrate surface level. Any missing clams were found and their depth in the tank noted. The tank was then dug out so that the original $0.3 \mathrm{~m}$ of sediment was left in the bottom and conditioned for the next burial event.

\subsubsection{Single Burial Event}

The initial experiments were designed to determine the effects of various depths in a single burial event and create an appropriate dose-response curve. Ranging trials were first done to provide a baseline, with target burial depths of $3 \mathrm{~cm}$ and $12 \mathrm{~cm}$ (the burial maxima found by modeling; Pearson et al. 2006). Subsequent trials were done to confirm the findings at the $12 \mathrm{~cm}$ level and deeper to find the lethal threshold. Actual depths for later experiments were determined by the results of the earlier experiments and guidance from the Corps.

Burials were performed once, as described above, for each burial depth tested. After the top was removed from the tank and the water cleared (usually 4 to 5 hours after burial), the tank was monitored for signs of razor clams activity at the sediment - water interface. Observations were made at least every 30 minutes during the first six hours, and periodically after that for the remainder of the 72 hours.

One burial trial was conducted with a few juvenile clams that were collected with the adult specimens. Four clams were placed in a single tank and buried under $12 \mathrm{~cm}$ of sand and observed as above. These data are reported but are not included in the analysis of adult clam responses. 


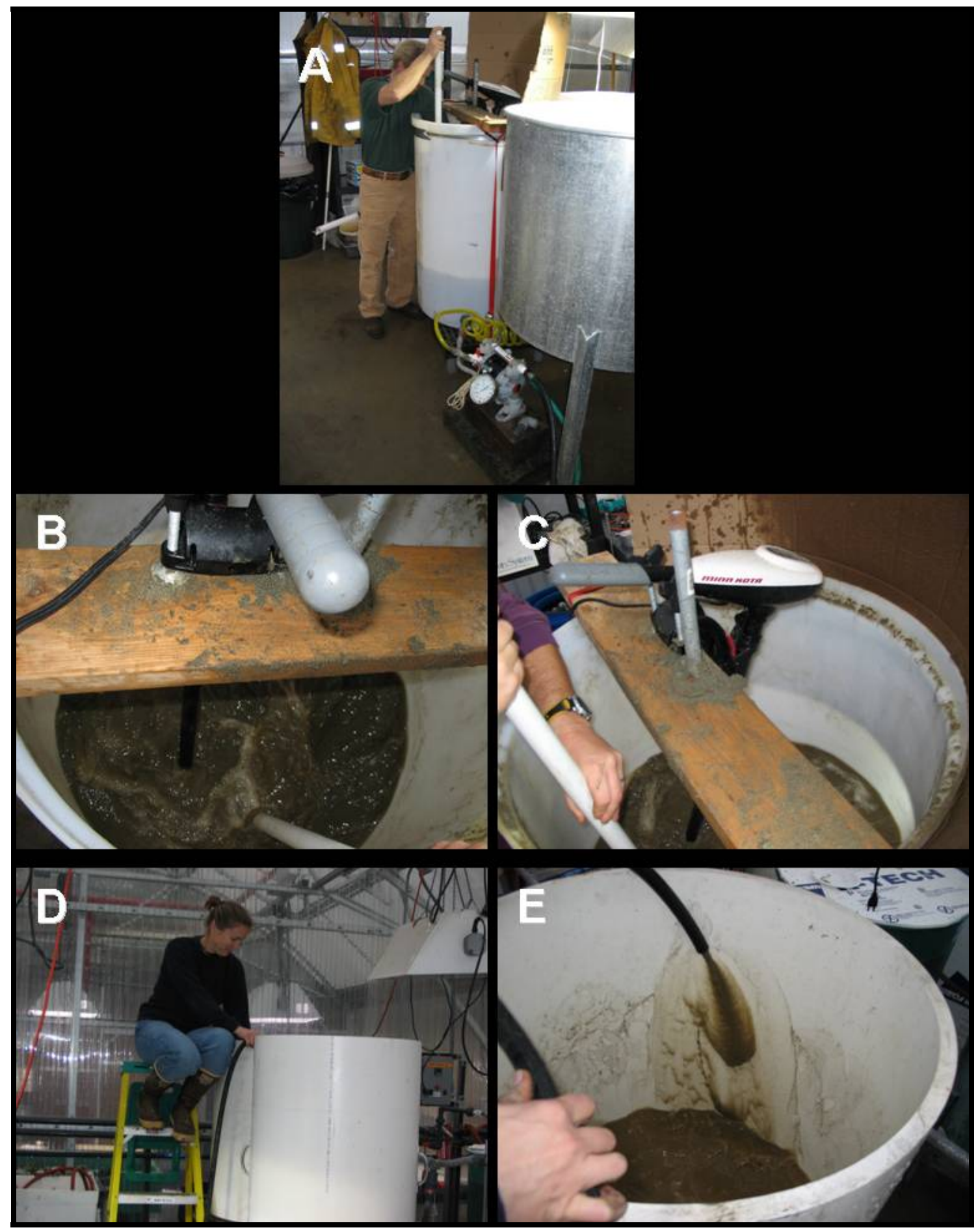

Figure 4. Photographs of some components of the burial sequence: A) mixing the slurry in the slurry tank; B) using the electric motor to mix the slurry; C) pole used to resuspend any settled sand in mixing tank; D) delivering the slurry to the experimental chamber; and E) the slurry entering the experimental chamber. 


\subsubsection{Sequential Burial Events}

After the ability of the razor clams to tolerate a single burial event was tested, a number of sequential burial trials were conducted. Several variables could be modified in these experiments (e.g. number of sequential burials, timing of burials, depth of the burial, etc.), but in order to maximize the results with a limited number of razor clams available, the decision was made (with guidance from the Corps) to focus on varying the time interval between disposal events. This time interval can be modified in actual dredge disposal operations more easily than the depth of burial. Sequential burial experiments were conducted with intervals of 4, 6, 8, and 24 hours between burial events. Burial depths were kept consistent at $12 \mathrm{~cm}$ as the maximum projected depth (and therefore a worst case scenario for interpretation of the results).

Burial in the sequential trials were conducted as outlined above with the single burial cycle repeated without resetting (i.e. digging out) the tank. The burial event was initiated and the tank was left for 4 hours (a little less in the 4 hour interval trials). The tanks were then partially drained and provided raw seawater. The depth of the burial layer was carefully measured without disturbing the clams in the experiment and new angled aluminum added to mark the new substrate surface. If the water cleared enough to see the substrate between burial events, observations were made to determine reemergence times. The top section of the tank was then reattached and another burial was conducted at the prescribed interval time. The experiment ended 72 hours after the last burial event or when all the razor clams regained the surface. 


\subsection{Results of Burial on Razor Clams}

We conducted 34 burial trials on razor clams from 8 September to 14 November 2006 (summarized in Table 2). Water temperatures varied from 8.1 to $13{ }^{\circ} \mathrm{C}$. Clams averaged $117.6 \mathrm{~cm}$ in length (range 100 to $141 \mathrm{~cm}$. There was no mortality in any of the controls during any trial. Specific results of the different burial scenarios are given in the sections below. Clams data were pooled within groups for analysis.

\subsection{Single Burial Experiments}

Results of razor clams survival in relation to differing burial depths are presented in Table 2 and Figure 5. The initial trials conducted at 3.5 and $12 \mathrm{~cm}$ burial depth showed $100 \%$ survival, so subsequent burial depths were selected to find an upper limit to the clam tolerance. Survival was still high (89\%) for razor clams buried under approximately $18 \mathrm{~cm}$ sediment and close to $70 \%$ for clams buried under $24 \mathrm{~cm}$. Extending the dose-response to deeper burials was not pursued: available clams were conserved for other trials because the depths tested were twice the maximum burial depth predicted by the STFATE model (Pearson et al. 2006) and clam survival was $100 \%$ within the projected burial depth range. Additional trials at the $12 \mathrm{~cm}$ burial depth were conducted to increase replication for the modeled maximum.

A single trial was also conducted with four juvenile clams with a $12 \mathrm{~cm}$ burial depth. These clams were $79,71,67$, and $65 \mathrm{~cm}$ (average $=70.5 \mathrm{~cm}$ ). Juvenile razor clam survival was $100 \%$ at a $12 \mathrm{~cm}$ burial depth.

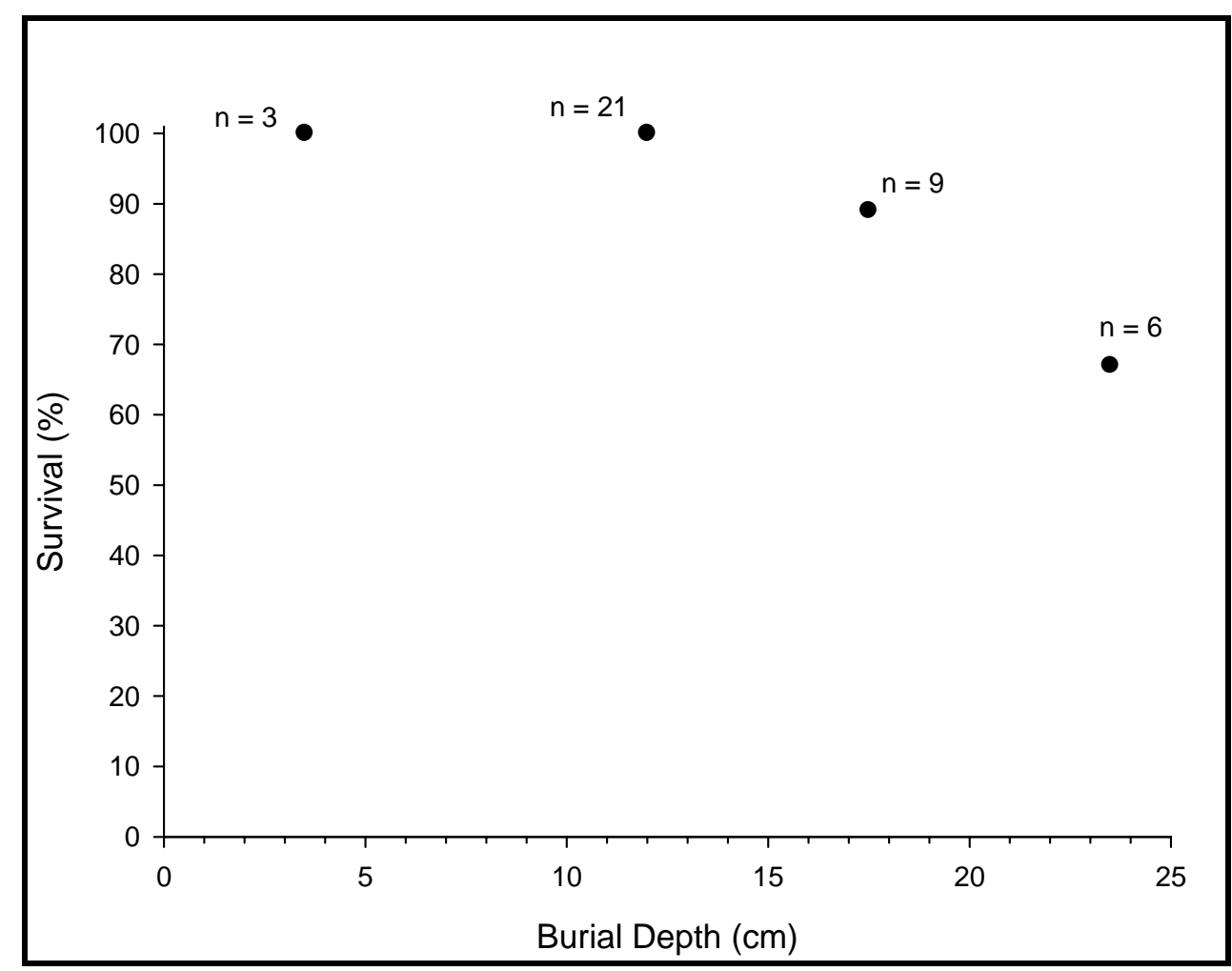

Figure 5. Survival of razor clams in relation to the depth of burial $(n=$ number of clams used $)$ 
Table 2. Results of single and sequential razor clam burial trials (dotted lines separate trials grouped together for analysis; trials are not listed chronologically).

\begin{tabular}{|c|c|c|c|c|c|c|}
\hline Objective & Trial ID & $\begin{array}{c}\text { Burial } \\
\text { Depth } \\
\text { (cm) }\end{array}$ & $\begin{array}{c}\text { Number in Series } \\
\text { of Multiple } \\
\text { Burials }\end{array}$ & $\begin{array}{c}\text { Interval Between } \\
\text { Multiple Burials } \\
\text { (h) }\end{array}$ & $\begin{array}{c}\text { Number } \\
\text { Clams } \\
\text { Tested }\end{array}$ & $\begin{array}{c}\text { Number } \\
\text { Clams } \\
\text { Surviving }\end{array}$ \\
\hline \multirow{16}{*}{$\begin{array}{l}\text { Single Burial } \\
\text { Depth }\end{array}$} & 1 & 3.5 & 1 & $\mathrm{n} / \mathrm{a}$ & 3 & 3 \\
\hline & 2 & 12 & 1 & $\mathrm{n} / \mathrm{a}$ & 3 & 3 \\
\hline & 3 & 12 & 1 & $\mathrm{n} / \mathrm{a}$ & 3 & 3 \\
\hline & 4 & 12 & 1 & $\mathrm{n} / \mathrm{a}$ & 3 & 3 \\
\hline & 5 & 12 & 1 & $\mathrm{n} / \mathrm{a}$ & 3 & 3 \\
\hline & 6 & 12 & 1 & $\mathrm{n} / \mathrm{a}$ & 3 & 3 \\
\hline & 7 & 12 & 1 & $\mathrm{n} / \mathrm{a}$ & 3 & 3 \\
\hline & 8 & 12 & 1 & $\mathrm{n} / \mathrm{a}$ & 3 & 3 \\
\hline & 9 & 17 & 1 & $\mathrm{n} / \mathrm{a}$ & 2 & 1 \\
\hline & 10 & 17.5 & 1 & $\mathrm{n} / \mathrm{a}$ & 3 & 3 \\
\hline & 11 & 18 & 1 & $\mathrm{n} / \mathrm{a}$ & 3 & 3 \\
\hline & 12 & 23 & 1 & $\mathrm{n} / \mathrm{a}$ & 3 & 2 \\
\hline & 15 & 24 & 1 & $\mathrm{n} / \mathrm{a}$ & 3 & 2 \\
\hline & 16 & 12 & 2 & 4 & 3 & 2 \\
\hline & 17 & 12 & 2 & 4 & 3 & 2 \\
\hline & 18 & 12 & 2 & 4 & 2 & 0 \\
\hline \multirow{18}{*}{$\begin{array}{l}\text { Sequential } \\
\text { Burials }\end{array}$} & 19 & 12 & 3 & 4 & 2 & 0 \\
\hline & 20 & 12 & 4 & 4 & 2 & 0 \\
\hline & 21 & 12 & 2 & 6 & 3 & 3 \\
\hline & 22 & 12 & 2 & 6 & 3 & 3 \\
\hline & 23 & 12 & 2 & 6 & 3 & 3 \\
\hline & 24 & 12 & 2 & 8 & 3 & 2 \\
\hline & 25 & 12 & 2 & 8 & 3 & 2 \\
\hline & 26 & 12 & 2 & 8 & 3 & 3 \\
\hline & 27 & 12 & 2 & 24 & 3 & 3 \\
\hline & 28 & 12 & 2 & 24 & 3 & 2 \\
\hline & 29 & 12 & 2 & 24 & 3 & 2 \\
\hline & 30 & 12 & 2 & 24 & 3 & 3 \\
\hline & 31 & 12 & 2 & 24 & 3 & 3 \\
\hline & 32 & 12 & 3 & 24 & 3 & 3 \\
\hline & 33 & 12 & 3 & 24 & 3 & 3 \\
\hline & 34 & 12 & 3 & 24 & 3 & 2 \\
\hline & 35 & 12 & 3 & 24 & 3 & 3 \\
\hline & 36 & 12 & 3 & 24 & 3 & 2 \\
\hline
\end{tabular}




\subsection{Sequential Burial Experiments}

The effects of multiple sequential burial events were tested in 21 trials (Table 2). Because initial trials with up to four burial events showed low survival (Table 2, Trials 16-20), subsequent trials focused on varying the time interval between sequential burial events. Razor clam survival when the burial events were in rapid succession was variable, ranging from $50 \%$ with a 4 hour interval and $100 \%$ at a 6 hour interval (Figure 6). Razor clam survival was $87 \%$ with a 24 hour interval between burial events. There were more than two burials conducted using 4 and 24 hour intervals (Table 2). No razor clams survived more than two burials at the four hour interval, but the survival at the 24 hour interval remained constant at $87 \%$ after the third burial.

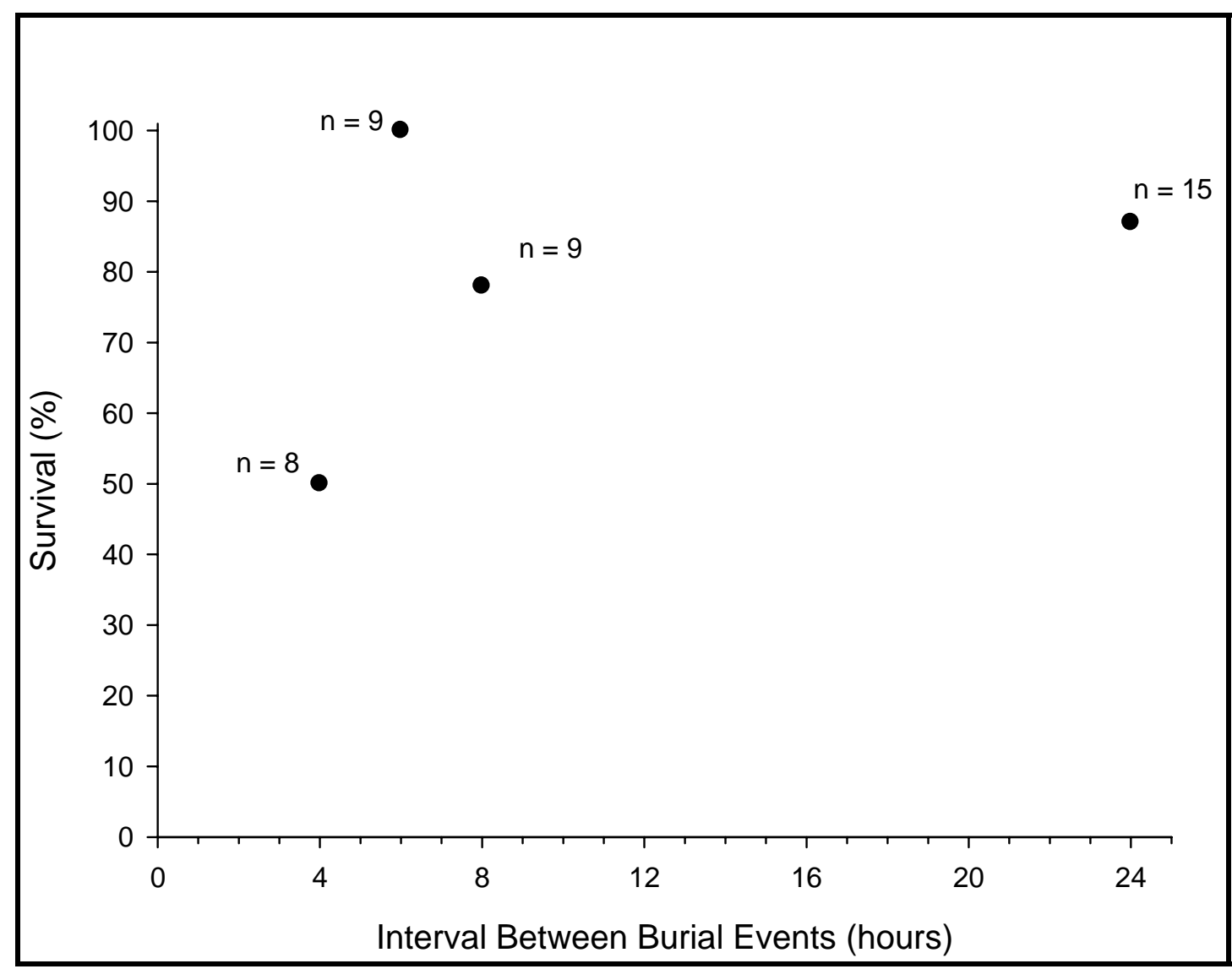

Figure 6. Survival of razor clams exposed to multiple burials with differing time intervals between events. Burial depth for each event was approximately $12 \mathrm{~cm}$. The number indicates the number of clams used at each interval 


\subsection{Re-emergence Time}

We attempted to determine how long it took clams to reemerge, or regain the sediment-water interface after a burial event. This proved more difficult than expected since the water stayed turbid for hours and different trials were starting at different times of the day due to varying intervals. However, it was possible to estimate some coarse reemergence time intervals from trials that were observed intensively for at least 8 hours after a burial event ( $\mathrm{n}=87$ clams). Based on the observation schedule, times were sorted into 5 categories: $<6 \mathrm{~h}, 6$ to $8 \mathrm{~h}, 8$ to $24 \mathrm{~h}, 24$ to $48 \mathrm{~h}$, and $>48 \mathrm{~h}$ after burial. Results (Figure 7) indicate that over $97 \%$ of clams had regained the sediment surface within 24 hours in all except the 4-hour interval sequential burials. In the 4-hour interval sequential burials, $50 \%$ of clams reemerged in the first 24 hours. The longest an individual took to regain the surface and survive was 70 hours, although there were only three individuals in the whole study that took longer than 36 hours (all in the 4-hour interval sequential burial trials).

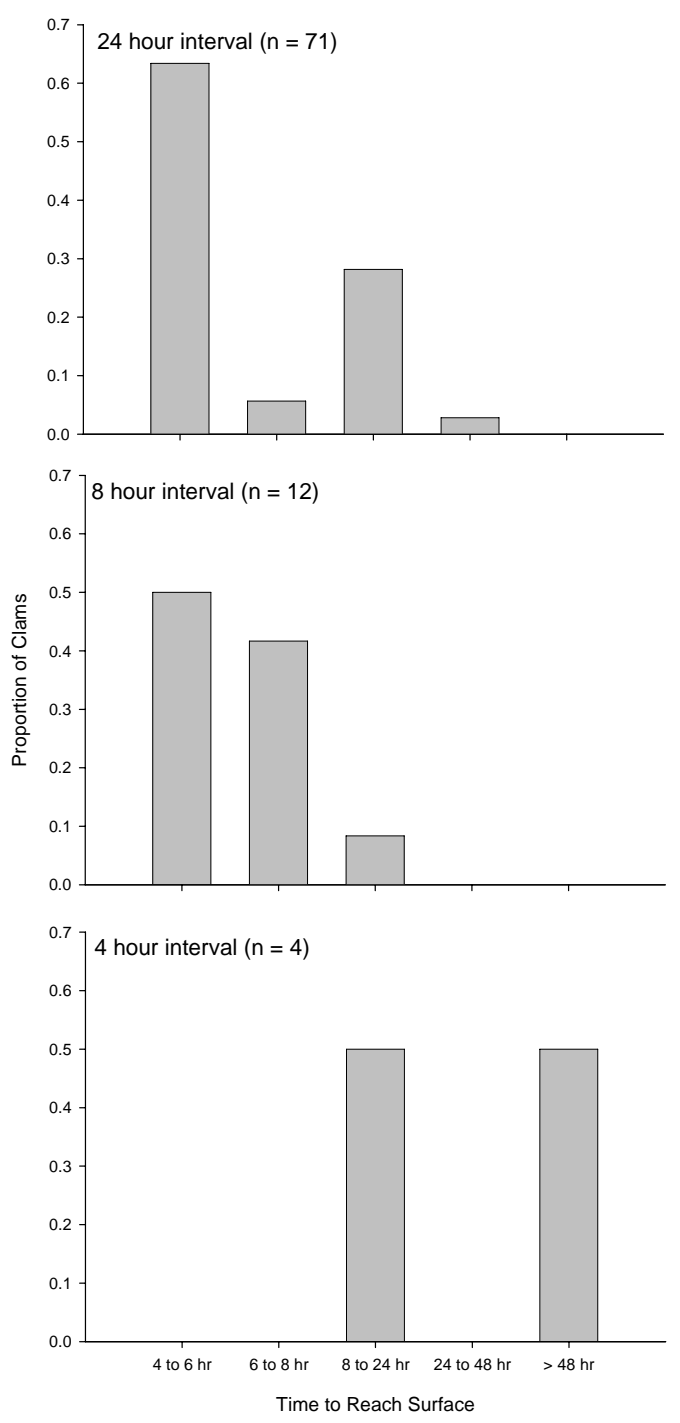

Figure 7. Reemergence times after burial for clams in three disposal scenarios ( $24 \mathrm{~h}$ interval included single burial trials). Number refers to the number of clams used in calculating the proportions. 


\subsection{Discussion and Conclusions}

The primary purpose for this study was to evaluate the potential impacts of dredge material disposal on adult subtidal razor clam populations at the mouth of the Columbia River. The laboratory results presented here have two implications for disposal operations.

First, the laboratory results from this study indicate that the razor clam populations can survive the range of burial depths expected from disposal events as the Corps currently conducts operations (i.e. single disposal in any location). The parameters needed to mimic these disposal events in the lab were provided from the STFATE model used in a previous study (Pearson et al. 2006). According to the model outcomes, a disposal event during typical operations would produce a maximum potential burial mound about $12 \mathrm{~cm}$ in thickness, and a mound of $12 \mathrm{~cm}$ height would cover an area of the sea bottom estimated at 9000 square meters. Our results suggest that razor clams can tolerate burial and then successfully regain access to the water column. Clam survival was $100 \%$ for burial up to $12 \mathrm{~cm}$, and survival was still high (70\%) when the $12 \mathrm{~cm}$ depth was doubled to $24 \mathrm{~cm}$ in a single disposal event (Figure 5).

Second, the laboratory results suggest that mortality is increased as the time intervals between burial events decrease. When the frequency of the disturbance was increased, clam survival decreased but was still relatively high (Figure 6). This is particularly apparent when comparing the 50\% survival after two $12 \mathrm{~cm}$ burial events four hours apart with nearly $70 \%$ survival in the single $24 \mathrm{~cm}$ burial event (both had the same overall burial depth). The mechanism that leads to the higher mortality with multiple burial events is unknown. The data here suggest that to minimize loss to the broodstock population there should be at least 24 hours in between disposal events. Most of the clams buried in one disposal event will be back at the surface after this time interval, and direct survival estimates are high. Trials that included a third disposal event at a 24-hour interval had the same survival as those with two (87\%) suggesting that clams that are able to survive two sequential disposal events can survive another of similar time interval. This was not the case when time interval between burial events was shorter ( 4 hours) and all clams died after a third event. Therefore it appears that the longer $(24 \mathrm{~h})$ interval should give the clams a chance to recover before the next burial.

Much of the literature on Siliqua patula razor clams describes the ability of the species to rapidly dig into the substrate to evade predators (including human harvesters). Some studies have found the rate of their burrowing to be one of the fastest for bivalves (McLachlan et al. 1995). Additionally, the mechanisms by which these burrowing bivalves dig have been fairly well documented for decades (e.g. Pohlo 1963, Trueman et al. 1966) and suggests that the physiology is primarily designed for descent by contraction of the large retractor muscles and resulting pull on the anchored foot. However little attention has been placed on the ability of the clams to move upwards, and no estimates of ascension rates were found. It is known that the clams live in dynamic, exposed areas (e.g. Lassuy and Simons 1989, McLachlan et al. 1995) and are therefore subject to frequent disturbances that may naturally bury individuals. Additionally it is also documented that these razor clams do not create a permanent burrow like many other burrowing bivalves (Pohlo 1963), which may also suggest the potential for disturbance in the environment is high. Therefore, while it could be assumed that the razor clams would be adapted to periodic disturbances, it 
was not known how razor clams would respond to or survive a dredged material disposal event prior to the experiments conducted in this study.

Some observations were made that may allow us to speculate on the process of ascension in razor clams after the burial event. Clams were always seen first by the siphon, and most times the shell was not seen until the clam was dug out. Additionally, a couple of dead clams were removed with their siphons completely extended through the sediment and their shells still close to the interface of original and new sand. This suggests that the clams are able to ascend in the same orientation as they burrow. They may be able to force their siphons up through the sediment and then follow this new channel with their shells. Further studies may verify these observations.

Several unanswered questions remain after this study. First, it is not known how smaller clams will do under similar burial conditions. This study specifically concentrated on mature individuals, but recruitment to these source populations may be threatened if mortality is higher in younger individuals. Many studies suggest that the juveniles of most burrowing bivalves can dig faster than their adult conspecifics (McLachlan et al. 1995). Faster digging rates however do not mean the smaller clams can dig as far a distance, and a $12 \mathrm{~cm}$ burial may be a dozen body lengths for small young of the year (YOY). It does appear that slightly smaller clams can survive at least a single disposal event based on our results,

but the clams used in this side experiment were still relatively large $(75 \mathrm{~mm})$ and not nearly the size of YOY (11 to $30 \mathrm{~mm})$.

There is also no way to estimate the effects of bottom scour after the dredge material encounters the bottom and spreads horizontally. The STFATE did not model the extent of the scour area although the model outcomes coupled with other information indicates that there is some potential for erosion of the bottom.

In conclusion, our results indicate that adult razor clams should exhibit high survival rates for the burial depths predicted to be encountered during single disposal events from typical operations in shallow (45 $\mathrm{ft}$ deep) disposal areas. If multiple disposal events are proposed for a site, our results show that an operational plan that does not allow for more than one disposal in 24 hours could prevent mortality seen in the laboratory at shorter intervals. 


\subsection{References}

Braun, G.M. 2005. Benthic infauna at the mouth of the Columbia River. Prepared for the Institute for Natural Resources at Oregon State University, by TetraTech EC, Inc. Bothell, Washington.

Galiani, J.Z., J.W. Smith, N.C. Kraus, D.D. McGee, E.B. Hands, C.J. Mayers, H.R. Mortiz, H.P. Mortiz, M.D. Siipola, D.B. Slocum, M.R. Byrnes, F. Li, T.L. Dibble, W.H. Hollings, C.R. Lund, C.K. Sollitt, and D.R. Standley. 2003. Monitoring dredged material disposal at mouth of Columbia River, Washington/Oregon, USA. Coastal and Hydraulics Laboratory ERDC/CHL TR-03-5. Prepared for the U.S. Army Corps of Engineers, Washington, DC.

Greenwood, S. 2005. Presentation to the Columbia River Nearshore Beneficial Use Project. 2 May 2005. http://inr.oregonstate.edu/download/nearshore project greenwood.pdf)

Hammermeister, T. 2006. Pilot Project Survey Results for Nearshore Beneficial Use of Dredge Material at the South Jetty of the Coumbia River. Prepared for the Lower Columbia Solutions Group, Portland, Oregon and the U.S. Army Corps of Engineers, Portland District, by SAIC, Bothell, Washington.

Lassuy, D.R. and D. Simons 1989. Species profiles: life histories and environmental requirements of coastal fishes and invertebrates: Pacific Northwest: Pacific Razor Clam. U S Fish and Wildlife Service Biological Report 82(11.89). U.S. Army Corps of Engineers, TR-EL-82-4.

McLachlan, A., E. Jaramillo, O. Defeo, J. Dugan, A. de Ruyck, and P. Coetzee. 1995. Adaptations of bivalves to different beach types. Journal of Experimental Marine Biology and Ecology 187:147160.

Pearson, W.H., M.C. Miller, G.C. Williams, N.P. Kohn and J.R. Skalski. 2006. Preliminary assessment of potential impacts to Dungeness crab from disposal of dredged materials from the Columbia River. PNNL-15477 Prepared for the U.S. Army Corps of Engineers, Portland District, by Battelle Marine Sciences Laboratory, Sequim, Washington. Published by Pacific Northwest National Laboratory, Richland, Washington.

Pearson, WH, GD Williams, and JR Skalski. 2005. Dungeness Crab Dredging-Entrainment Studies in the Lower Columbia River, 2002-2004: Loss Projections, Salinity Model, and Scenario Analysis. PNNL-15021. Prepared for the U.S. Army Corps of Engineers, Portland District, by Pacific Northwest National Laboratory, Marine Sciences Laboratory, Sequim, Washington.

Pohlo, R.H. 1963. Morphology and mode of burrowing in Siliqua patula and Solen rosaceus. The Veliger 6:98-104.

Schink, T.D., K.A. McGraw, and K.C. Chew. 1983. Pacific Coast clam fisheries, University of Washington. HG-30. 
Truman, E.R., A.R. Brand, and P. Davis. 1966. The dynamics of burrowing in some common littoral bivalves. Journal of Experimental Biology 44:469-492. 
PNNL-16350

\section{Distribution}

No. of

Copies

OFFSITE

6 K.W. Larson

U. S. Army Corps of Engineers

Portland District

Environmental Resources CENWP-PE-E

P. O. Box 2946

Portland, OR 97208-2946

1 W.H. Pearson

332 Viewcrest Avenue

Port Angeles, WA 98362
No. of

$\underline{\text { Copies }}$

\section{ONSITE}

3 Pacific Northwest National Laboratory

J. Vavrinec

SEQUIM

N.P. Kohn

SEQUIM

Information Release

K1-06 